\title{
Approaches in Developing Undergraduate IT Engineering Curriculum for the Fourth Industrial Revolution in Malaysia and Vietnam
}

\author{
Tran Thi Bich Lieu ${ }^{*}$, Nguyen Huu Duc²\#, Nancy Webster Gleason ${ }^{3,4}$, Duong Trong Hai 5,6, \\ Nguyen Duy Tam ${ }^{7}$
}

${ }^{1}$ VNU University of Education, Vietnam National University, Hanoi, Vietnam

${ }^{2}$ Vietnam National University, Hanoi, Vietnam

${ }^{3}$ The Centre for Teaching and Learning, Yale-NUS College, Singapore

${ }^{4}$ Global Affairs, Division of Social Sciences, Yale-NUS College, Singapore

${ }^{5}$ Department of Information Technology, Nguyen Tat Thanh University, Hochiminh City, Vietnam

${ }^{6}$ Institute of Science and Technology of Industry 4.0, Nguyen Tat Thanh University, Hochiminh City, Vietnam

${ }^{7}$ School of Materials Science and Engineering, Nanyang Technological University, Singapore

Email: *lieutran5@yahoo.com, ducnh@vnu.edu.vn,nancy.gleason@yale-nus.edu.sg, haiduongtrong@gmail.com,

tamnguyen@ntu.edu.sg

How to cite this paper: Lieu, T. T. B., Duc, N. H., Gleason, N. W., Hai, D. T., \& Tam, N. D. (2018). Approaches in Developing Undergraduate IT Engineering Curriculum for the Fourth Industrial Revolution in Malaysia and Vietnam. Creative Education, 9, 2752-2772.

https://doi.org/10.4236/ce.2018.916207

Received: October 17, 2018

Accepted: December 10, 2018

Published: December 14, 2018

Copyright $\odot 2018$ by authors and Scientific Research Publishing Inc. This work is licensed under the Creative Commons Attribution International License (CC BY 4.0).

http://creativecommons.org/licenses/by/4.0/

CC) (7) Open Access

\begin{abstract}
Curricula have important effects on students' professional skills. To prepare for the fourth industrial revolution (4IR), countries are recommended to implement new curricula to develop new competencies for the automation workforce. As Information technology (IT) lays the foundations for the core 4IR-relevant emerging technologies (big data, internet of things, artificial intelligence, etc.), countries have developed new IT engineering curricula to prepare engineers for the 4IR. By conducting a structured focused comparison for bachelor IT curricula containing core 4IR modules of 57 Vietnamese and 35 Malaysian universities, this research aims to find appropriate approaches in developing curricula to prepare 4IR competencies for IT engineering students for Malaysia, Vietnam and implications for other nations. The research found that, only new stand-alone curricula with a focus on 4IR competencies can prepare engineers for the 4IR. It then provides seven lessons for designing new 4IR engineering curriculum and for continuing studies on 4IR-ready curriculum.
\end{abstract}

\section{Keywords}

Fourth Industrial Revolution (4IR), Information Technology (IT), 4IR Engineering Competencies, 4IR Undergraduate IT Engineering Curriculum, Malaysian Higher Education, Vietnamese Higher Education 


\section{Introduction}

The Fourth Industrial Revolution (4IR) has already dramatically impacted many aspects of manufacturing, business, education, health sciences, as well as social and cultural life around the world. Countries have to prepare for the 4IR in order to stay viable in the global economy and therefore must prepare their populations for the pending shifts in how we work (Kurdahi, et al., 2016; WEF, 2016). The WEF and A.T. Keaney (WEF \& Keaney, 2018) reported on the 4IR-readiness of 100 countries according to twelve identified core technology-related innovations. These core areas are: big data, artificial intelligence (AI), and internet of things (IoT), virtual and augmented realities, additive manufacturing, blockchain and distributed ledger technology, advanced materials and nano-materials, energy capture, storage and transmission, new computing technologies, biotechnologies, geoengineering, neurotechnology, and space technologies. The WEF explains readiness for the changes these technologies are bringing as operating on scale from: 1) Leading; to 2) High potential; to 3) Legacy; and finally 4) Nascent readiness. Six main drivers were used to measure the readiness, including: Technology \& Innovation, Human Capital, Global Trade \& Investment, Institutional Framework, Sustainable Resources, and Demand Environment. In this report WEF identified Malaysia as one of 25 countries that are "ready" for the 4IR relative to other countries, while Vietnam's readiness is characterized as "nascent" (WEF \& Kearney, 2018). By human capital, Malaysia is ranked 21/100, while Vietnam is ranked 70/100. Human resources are often a decisive factor for the socio-economic development of a country (WEF, 2016). To prepare for the 4IR, WEF recommends countries to develop their future workforce through new training approaches with new education curricula (WEF \& Kearney, 2018). As IT lays the foundations for 4IR-related manufacturing and for the emerging multi-disciplinary technologies such as cyber-physical systems (CPSs), IoT, AI, and big data, countries are changing and developing new curricula to improve key skills for the workforce (Iscoop, 2017; Kurdahi, et al., 2016; Törngren, et al., 2017). Vietnam and Malaysia are countries both in the Southeast Asian region having some historical, economic and cultural similarities, but the difference in the level of $4 \mathrm{IR}$ readiness raises questions for Vietnam to study. As curricula have important effects on students' professional skills (Carter, et al., 2016), through analyzing and comparing 4IR-relevant IT engineering curricula, the research aims to clarify appropriate approaches in developing 4IR engineering curricula. It also aims to highlight correlational difference in 4IR readiness of human capital between the two countries and reasons for the differences from an educational policy perspective. The findings contribute knowledge of new trends in preparing IT engineering students for the 4IR and lessons for universities in designing new 4IR engineering curricula for the future economy.

This article first introduces the technological nature of the 4IR, competencies required for engineers to become experts in these 4IR technologies, requirements of relevant engineering curriculum to prepare students appropriately and 
contexts of Malaysia and Vietnam higher education relating to the practical implementation of the 4IR engineering preparedness. Then it analyses and compares similarities and differences of IT curricula of Malaysian and Vietnamese universities to identify the trends in developing 4IR-relevant engineering curricula in Malaysia and in Vietnam. The analysis and comparison focus on big data, IoT, AI and on CPSs coverage in higher education (HE) curricula. The article concludes with recommendations for universities to apply appropriate approaches in developing 4IR curricula for undergraduate IT engineers to better prepare a 4IR-ready workforce.

\section{The Fourth Industrial Revolution Engineering Competencies and Curriculum}

The relationship among 4IR, engineering competencies and relevant curriculum are described in Figure 1.

Iscoop (2017), Kurdahi, et al. (2016), and Törngren, et al. (2017), have all identified big data, IoT, and AI as integrated systems that support each other to develop intelligent machines and CPSs, making up the key elements of the 4IR.These authors explain that, the 4IR is a CPS-based industry that connects virtual (e.g. cyber space, knowledge, information, cyber-social world, cloud...) and physical (e.g. smart devices, sensors, actuators, computers, physical assets, customers) systems to create integrated, intelligent, and safe, high performance automation systems in different socio-economic fields. For engineers, Crawley, et al. (2007) emphasize that they should have expertise in a particular industry to carry out practical implementation in industrial and social contexts in addition to competencies in different industrial fields. Therefore, 4IR engineers should have competencies in a specific field of 4IR technologies. The US National Academy of Sciences, Engineering, and Medicine (2016), and Törngren, et al. (2015), both highlight the importance of developing CPS skills that enable people to realize physical and cyber connections and thus to differentiate CPS engineers from experts in other fields of computer science, control, and communication. The US National Academies of Sciences, Engineering, and Medicine (2016) lists the following foundational knowledge necessary for educating a CPS-ready workforce: 1) Basic computer concepts; 2) Computing for the physical world; 3) Discrete and continuous mathematics; 4) Cross-cutting application of sensing, actuation, control, communication, and computing; 5) Modeling of

\begin{tabular}{|c|c|c|c|c|}
\hline $\begin{array}{c}\text { 4IR } \\
\text { Emerging core } 4.0 \\
\text { technologies (3D, } \\
\text { big data, IoT, AI, } \\
\text { CPSs, blockchain...) }\end{array}$ & $\Leftrightarrow$ & $\begin{array}{l}4.0 \text { engineering competencies: } \\
\text { including: specific core } 4.0 \\
\text { technology, interdisciplinary } \\
\text { industrial\& general } \\
\text { competencies (creativity, } \\
\text { collaboration, entrepreneurial, } \\
\text { lifelong learning) }\end{array}$ & $\Leftrightarrow>$ & $\begin{array}{l}\text { 4.0 engineering curriculum: } \\
\text { The new curricula of core } \\
4.0 \text { technologies which focus } \\
\text { on } 4 \text { IR engineering } \\
\text { competencies. } \\
\text { Interdisciplinary \& } \\
\text { transdisciplinary }\end{array}$ \\
\hline
\end{tabular}

Figure 1. Relationship among 4IR, engineering competencies and engineering 4IR core technology curriculum. 
heterogeneous and dynamic systems integrating control, computing, and communication; and 6) CPS system development.

Big data as defined by Kalantari, et al. (2017) and Monnappa (2017) includes the "fourVs": volume, velocity, variety and veracity of data (text, audio, visually) that are shared, transferred and used for different purposes in different fields. These four Vs are what distinguish big data from traditional data. The IoT is a disruptive technology which involves a swarm of sensors that connect all sub systems, processes, both internal and external objects, network providers and customers to allow them all to communicate and collaborate with each other and machines with humans (Zanni, 2015). AI is a non-biological, "designing" intelligence (Spector, 2006). It involves the creation of intelligent machines that work and react like humans and play important roles in human society. Robotics is a major field related to AI, but involves the mechanization of human capabilities. For big data, robotics, and AI, engineers need to have specific, but integrated competencies of each area and among areas. Some core knowledge and skills in big data curricula are suggested by Molluzzo, Lawler (2015) and Monnappa (2017). They argue that big data analytics, big data foundation, data science, data warehousing, data visualization, machine learning and data mining are all skills that need to be integrated into the engineering curriculum. Whereas IoT engineers need to gain new knowledge and skills in sensors, perception, cloud management, cyber-security, big data management, integrating smart objects into IoT framework (s) (Koo, 2015). AI engineers need to know human language and machine interactions, robot hardware and control software skills, data science, kinematics, and estimation knowledge (Spector, 2006; Wyatt, 2000). These are all areas that have typically been included in engineering education. IoT, AI and big data curricula content cover some similar areas of knowledge relating to computing, intelligent systems, mathematics, data, as well as knowledge specific to IoT, AI and big data (Koo, 2015; Nilsson, 1998). As these are relatively new technologies and capacities in computing, curriculum in higher education needs to quickly integrate them in order to prepare their graduates for the work ahead.

The 4IR is characterized by these technologies cooperating with each other and with humans in integrated systems that change how we live and work (Infosys, 2017). Besides such specific competencies noted above, engineers, according to those authors (Hecklau, et al., 2016; National Academies of Sciences, Engineering, and Medicine, 2016; Rajkumar, 2012; Passow \& Passow, 2017; Törngren, et al., 2015; Weltzien, 2016), should be trained to integrate knowledge across a range of industries; and should be multi-functional people with personal and social competencies. They should have interdisciplinary and system knowledge, competencies of creativity and entrepreneurship, lifelong learning, and be able to solve complex problems and make decisions based on big data. It is also very important that students are trained in social emotional competencies in which, they have the ability to collaborate and communicate beyond technology requirements. In addition, they need to obtain project management skills to in- 
teract with stakeholders in other fields. Specifically, Passow, J. H. \& Passow, C.H. (2017) emphasize coordinating multiple competencies to accomplish a goal as a crucial skill for engineers. This includes demand in for the general competencies of collaboration, lifelong learning, creativity and entrepreneurship.

Curricula have important effects on students' professional skills (Carter, et al., 2016). Academic curriculum goes through designing and implementing stages. The result of the first stage is a curriculum framework with identification of student learning outcomes that meet social and economic development requirements. The learning outcomes involve student competencies developed during the instructional processes in- and outside the classroom. Curriculum frameworks as an academic plan contains a number of elements, including philosophy; learning outcomes, models; organization and structure; teaching, learning and assessment strategies; module design. These elements are appropriate to the outcomes and a set of instructional techniques and learning aids to help learners achieve the goals, and measure these intended outcomes (O'Neill, 2015; Stark, 1986). To prepare for the $4 \mathrm{IR}$, WEF recommends countries to use new training approaches and new education curricula to develop their future workforce (WEF \& Kearney, 2018). Tackling coverage of all these important areas cannot be effectively done in the traditional siloed higher education constructs. The traditional curricula are criticized for lacking integration of disciplines, focusing almost exclusively on theory and single subject teaching and learning (Crawley, et al., 2007). This form of information transfer does not equip students with the cognitive skills, let alone content skills, necessary for the 4IR economy. Therefore, to form the needed 4IR competencies, emphasis on general and professional skills is required, broadened instructional methodologies, interdisciplinary and transdisciplinary teaching and learning, and research-led project-based learning needs to be integrated into HE engineering pedagogy. Importantly for 4IR competencies virtual laboratory practices need to be developed, and co-curricular activities and experiential learning need to be better funded and integrated (Carter, et al., 2016; Gleason, 2018; Janssen, et al., 2106; Möller, \& Vakilzadian, 2016; Tisch, et al, 2016). Connections of academia with industrial and business companies are necessary to implement work based learning and practice to solve problems for the global community (National Academy of Sciences, Engineering and Medicine, 2017). In the twenty-first century, with increasing systems complexity, the curriculum should be interdisciplinary and transdisciplinary. In an interdisciplinary curriculum several disciplines are merged into a subject area and interdisciplinary connections and methods are deployed among curriculum elements (Crawley, et al., 2007; O'Neill, 2015; Stark, 1986). Transdisciplinary curriculum merges different disciplinary areas. For example, CPS education has a multidisciplinary nature drawing from several academic disciplines due to the complexity of the systems (Haque, et al., 2014; Törngren, et al., 2015). AI, big data, IoT have an inter-disciplinary nature as well and they are sometimes combined with other disciplines to form new technology 
fields (Cicirello, 2008; Ergezer, et al., 2018; Koo, 2015; Molluzzo \& Lawler, 2015; Wyatt, 2000).

To satisfy these requirements, the Massachusetts Institute of Technology (MIT) developed the Conceive - Design - Implement - Operate (CDIO) approach to teaching engineering. According to $\mathrm{CDIO}$, an interdisciplinary curriculum must content four following discipline blocks: 1) general courses that equip students with general competencies, 2) professional core and 3) specialization courses, and 4) elective courses; practicum/professional application is incorporated in professional courses to equip students with necessary competencies for their job. CDIO encourages developing interdisciplinary and specific industrial professional, personal and interpersonal competencies for engineers through experiential learning with real-world systems that operate within a framework of curricular planning and outcome-based assessment (Crawley, et al., 2007).

\section{Vietnamese and Malaysian Higher Education in the 4IR Context}

Malaysia and Vietnam are both emerging economies in Southeast Asia and both are beginning to prepare for the 4IR, however with different levels of success. In Malaysia, the Government developed a National Industry 4.0 Policy Framework. It aims to accelerate Malaysia's transformation into a smart and modern manufacturing nation and puts preparation of the $4 \mathrm{IR}$ workforce as a top priority (Ministry of International Trade and Industry, 2016). In response to the Government initiative, the Ministry of Higher Education (MoHE) just promulgated a framework for HE 4.0 with emphasis on developing new 4IR relevant curricula (MoHE, 2018). The Government is planning to allocate RM 50 million (around 1.3 million USD) from $30 \%$ of the Human Resources Development Fund to train citizens in 4IR-relevant skills (Malaysian Digest, 2017). As mentioned above, Malaysia is among the top 25 countries identified as leading in readiness for the 4IR, and this is linked in part to the higher education reform efforts in that country.

In Vietnam, the government seeks to foster a knowledge-based economy, emphasizing human capacity in creativity as a priority. In May 2017, Vietnam's Prime Minister issued Decision No. 16/CT-TTg "On Strengthening Access to the Fourth Industrial Revolution". The statement declared that 4IR has already had a profound impact on Vietnam and it represents an opportunity for the country to develop its new service and business models, while supporting innovative start-ups. The Decision calls for the development of human resources to meet the shifting demands of world production in the automation economy. The Ministry of Education and Training (MOET) is tasked with "raising the capacity of research and teaching in tertiary education institutions; strengthen the education of basic skills, knowledge, creative thinking and adaptability to the requirements of the 4IR." (Thư tướng Chínhphủ, 2017). The technologies of the 4IR 
have arrived and Vietnam is supporting advancements of the country's development. However, Vietnam has been ranked as having only "nascent readiness" for the 4IR according to the WEF 2018 report. The nation has acknowledge the challenges and some of the ways forward, but has not yet put in place in the educational shifts necessary.

In both countries, the universities, especially in the area of IT-related education, have been changing their curricula and training conditions to meet the requirements of educating 4IR-ready competencies, but with varying degrees of scale and impact. The speed of change is slow in Vietnam, while Malaysia is adapting quickly. The academic curriculum is one of the factors leading to disparities in preparation of human capacities in the two countries.

\subsection{Malaysian Higher Education}

During the last fifteen years, the Malaysian HE system has made significant advancements in student enrolment, and has risen in global rankings in key dimensions such as research publications, patents, and institutional quality and international students. Substantial increases in access were achieved between 2004 and 2012, realizing 1.2 million students enrolled, or 70\% of the demographic grouping in the tertiary age range (Ministry of Education (MOE), 2015). The Malaysian HE landscape consists of different types of public and private universities, colleges, and technical and community colleges. The country has 20 public universities, but also has 497 private colleges and universities. The number of university academic staff was 68,264 (Omar, 2017). By QS ranking in $2018^{1}, 16$ public and 11 private institutions were in the top $100-400$, of which five research universities were in the top 50 . There are 52 subject areas within Malaysian universities that are within the top 100 world ranking, although these do not include the IT disciplines. The quality of these institutions is further evidenced by the fact that, according to Omar (2017), Malaysia among the top 1\% of globally cited researchers. The universities also experienced an increased scientific publication and citation rate up to $3.1 \times$ and $4.0 \times$ (highest in the world), and patents up to $40 \%$ during 2000-2013. Signaling this strength, collaborations with industry, NGOs and agency consultations brought in 300 million USD for the country. According to Universitas 21 annual report, which produces an index comparing national HE systems for 50 countries, Malaysia is ranked 12 out of 50 in terms of resources invested, and $44^{\text {th }}$ out of 50 for outputs (MoE, 2015).

In response to Government efforts, the Malaysian Ministry of Higher Education (MMoHE) (2015) is seeking to create an HE system that ranks among the world's leading education systems. There is a strong emphasis on developing entrepreneurial mindsets, outcomes over inputs, technologies and innovations, lifelong learners, and the development of future-ready talents. The MMoHE

${ }^{1}$ https://afterschool.my/find-university-in-malaysia/which-malaysian-universities-ranked-on-the-qs -asia-university-rankings. 
(2018) proposed a curriculum content for eleven different 4IR-relevent technologies for students; these include: AI, robotics, augmented reality, IoT, cyber-security, new business models, cloud computing, supply chain, additive manufacturing, simulation, and horizontal and vertical integration. The MMoHE suggests a balance of 4IR-relevant knowledge and skills (ilmu) combined with 4IR-relevant ethics and morality (akhlak) in developing student competencies. To form competencies for 4IR, MMoHE recommends shifting from a simple mixture of disciplines into an inter- and trans-disciplinary content focus. MMoHE is calling for work-based learning programs to increase student employability; intensifying collaboration between academia and industry (two years or one year of hands-on practice in industry), massifying HE through MOOCs, and creating innovative ecosystems and developing student digital portfolios which reflect their real competencies.

\subsection{Vietnamese Higher Education}

Over the last several decades, Vietnamese HE has improved in both access and quality. The HE system has diversified as well with many public and private school options emerging. According to the Vietnamese MOET statistics (7/2017), the total number of universities was 235 , including 170 public universities (composed of national, regional and local institutions) and 65 private universities with the number of students being $15 \%-16 \%$ of the $18-24$ age group and $22.7 \%$ of faculty having a doctorate degree. By QS rankings in 2018, Vietnam does not have as many HE schools in the rankings as Malaysia: two National Universities in Hanoi and Hochiminh City are in the top 100 - 200, and there are three others in the top $300-400^{2}$. Although the country and MOET have not developed specific strategies to meet the 4IR requirements, in the 2017-2018 academic year MOET asked universities to standardize their faculty, increase their research, English, IT and international integration capacity; secure appropriate equipment for training students to meet the real needs of the labor markets that have been changing towards the industry 4.0 manufacturing fields. Vietnam has always identified education as the top national priority, but challenges of quality and funding remain (MOET, 2017). Vietnamese universities currently emphasize training IT engineering students with some 4IR-relevant knowledge. But the curriculum remains siloed in academic departments, and knowledge transfer is prioritized, leaving little space for assessment that develops creativity and critical thinking in students (Tran, et al., 2014).

\section{Research Design}

\subsection{Research Question}

The 4IR requires workforce to have 4IR competencies that can be developed by new 4IR curricula. Computer science competencies and IT-focused education provide foundations of knowledge and skills for different 4IR industries. As a 
result, IT departments at Vietnamese and Malaysian universities are beginning to focus on educating engineers with 4IR competencies by developing new 4IR curricula or embedding core 4IR courses in the existing IT curricula. This research asks:

1) What approaches are appropriate to change/develop IT undergraduate engineering curricula to meet new requirements in educating engineers for the $4 \mathrm{IR}$ ?

2) What are the unique characteristics of Malaysia's IT engineering curricular approaches in 4IR-relevant competencies that contribute to Malaysia's leading $4 \mathrm{IR}$ readiness and how do they compare to those of Vietnam?

\subsection{Research Aim}

This research has the following threshold aims: 1) to identify appropriate approaches in developing curricula to prepare 4IR competencies for undergraduate IT engineering students; 2 ) to compare undergraduate IT engineering education in Malaysia and Vietnam and identify correlational differences to their respective 4IR readiness; and 3) to suggest improvements in preparing engineers for the 4IR for both Malaysia and Vietnam and share implications for other nations.

\section{Methods and Data Collection and Analysis}

Document analysis is an important research method related to categorizing content. Curriculum documents work as physical evidence in the document analysis research method (Bowen, 2009). This study used document analysis as a qualitative research method to conduct a structured focused comparison of university IT curricula in Vietnam and Malaysia.

The study reviewed and analyzed engineering bachelor IT curricula containing 4IR-relevant modules across 57 Vietnamese and 35 Malaysian universities' IT departments that were available on the universities' website (Table 1). Emphasis is placed on the core 4IR competencies in curricular areas of IoT, big data, AI, and CPSs. After reviewing 235 universities in Vietnam, of which 35 had no IT departments, we found $70 \%$ of universities (140/200) that have specialized IT training curricula, but only 41\% (57/140 universities) that have embedded core 4IR modules in their IT curricula. In Malaysia, out of 74 examined universities, 54\% (40/74) had IT departments. Of the 40 IT departments, $86 \%(35 / 40)$ have IT programs with core 4IR-relevant subjects.

Table 1. Sample of IT departments with core 4IR technologies related curricula of Vietnam and Malaysia.

\begin{tabular}{cccc}
\hline & Total & Public & Private \\
\hline Malaysia & $35 / 40(86 \%)$ & $16 / 35(46 \%)$ & $19 / 35(54 \%)$ \\
Vietnam & $57 / 140(41 \%)$ & $39 / 57(68 \%)$ & $18 / 37(32 \%)$ \\
Total & 92 & 55 & 37 \\
\hline
\end{tabular}


Using 4IR competencies requirements for engineers, based on the interdisciplinary curriculum structure suggested by CDIO, this study categorized curricula and compared their similarities and differences according to the following criteria areas: 1) 4IR core technologies education focus and 4IR curricula outcomes for specific 4IRtechnologies; 2) Integration of core 4IR technologies competencies with general competencies (Creativity and entrepreneurship, lifelong learning, and collaboration); 3) Experiential nature of curriculum for industrial practice, project based learning, and interdisciplinarity that supports implementation of outcomes in the curricula.

\section{Results and Discussion}

\subsection{More Focus on 4IR Curricula of Malaysian Universities}

Table 1 shows that $86 \%$ of the IT departments in Malaysia focused on training core 4.0 technologies and there was a balance between public and private universities in providing training core 4.0 technologies. In Vietnam only $41 \%$ of the IT departments provided 4IR relevant technologies training, as compared to $86 \%$ of the departments in Malaysia and more public universities than private universities focused on educating engineering students 4.0 technologies (68\% compared to $32 \%$ ). The research identified an important distinction between the various curricula that cover the core 4IR technologies (Table 2). Table 2 shows that, there were some 4.0 technology courses embedded in the existing educational programs, and others were developed from scratch and operate as a new program within their institutions. Table 2 delineates which 4IR-relevant technologies are covered in which country as coded by embedded or as new curricula.

Table 2 demonstrates that the bachelor-level IT curricula of both countries contained core 4IR-relevant technologies, including IoT, big data or AI. However, the analysis shows two distinct approaches in providing these core 4IR-relevant curricula. Some institutions embedded the content in existing curricula while others are developing new curricula to stand on its own. Malaysia tended to have new curricula developed relating to 4IR-relevant technologies and skills, whereas Vietnam had mostly focused on embedding such material in existing courses and programs.

There is also a noticeable lack of coverage of CPS in either newly developed courses or in existing curricula. The transition to CPS research is still emerging around the world. The same situation as identified in Vietnam and Malaysia was found in other lower income countries. For example, Sackey and Bester (2016) found the lack of CPS-emphasis in industrial engineering curricula in South African Universities. This is problematic for preparing future-ready engineers for the 4IR economy. Moving forward, engineered systems will all involve CPS technologies; therefore curricula and programs need to respond accordingly. 
Table 2. Number of bachelor curricula with coverage of 4IR-relevant core technologies in Malaysia and Vietnam.

\begin{tabular}{|c|c|c|c|c|c|c|c|c|c|c|}
\hline \multicolumn{6}{|c|}{ Malaysia } & \multicolumn{5}{|c|}{ Vietnam } \\
\hline \multirow[t]{2}{*}{$\begin{array}{l}\text { Curriculum } \\
\text { with core } \\
\text { 4.0industries }\end{array}$} & \multirow[t]{2}{*}{ Total } & \multicolumn{2}{|c|}{ Embedding } & \multicolumn{2}{|c|}{$\begin{array}{c}\text { New } \\
\text { development }\end{array}$} & \multirow[t]{2}{*}{ Total } & \multicolumn{2}{|c|}{ Embedding } & \multicolumn{2}{|c|}{$\begin{array}{c}\text { New } \\
\text { development }\end{array}$} \\
\hline & & Public & Private & Public & Private & & Public & Private & Public & Private \\
\hline AI & 43 & 16 & 19 & 05 & 03 & 57 & 39 & 18 & 0 & 0 \\
\hline IoT & 0 & & & & & 05 & 05 & 0 & 0 & 0 \\
\hline $\mathrm{BD}$ & 0 & & & & & 06 & 04 & 02 & 0 & 0 \\
\hline $\mathrm{AI}+\mathrm{BD}$ & 03 & $01^{3}$ & $02^{4}$ & & & 04 & $04^{5}$ & & & \\
\hline $\mathrm{IoT}+\mathrm{AI}$ & 01 & & $\begin{array}{l}\text { IoT major+ } \\
\text { BD minor }\end{array}$ & & & 01 & $01^{7}$ & & & \\
\hline $\mathrm{AI}+\mathrm{BD}+\mathrm{IoT}$ & 01 & & $01^{8}$ & & & 01 & $01^{9}$ & 0 & & \\
\hline CPSs & 0 & & & & & 0 & & & & \\
\hline $\begin{array}{c}\text { Cloud } \\
\text { Computing } \\
\text { Technology }\end{array}$ & 02 & & & & $02^{10}$ & 0 & & & & \\
\hline
\end{tabular}

\subsection{Differences of 4IR Competencies in the Embedding and New Developing 4IR Curricula}

1) Embedding core 4IR Technologies in the existing curricula

In Vietnam most of the 57 4IR-related curricula review included separate IoT or big data or AI content, but lacked new specific or interdisciplinary curricula in these fields. Only Hanoi University of Science and Technology offered three elements of IoT, big data and AI in the curricula, but most were selective modules and for only talented students. The University of Information Technology at Vietnam National University in Hochiminh City (VNUHCM) provided CPSs, IoT, big data and AI related research topics, but only for doctoral degrees. Similarly, Malaysia's Taylor University's bachelor of computer science had an embedded module on robot design as well as a minor in the existing curriculum. This curriculum included selected options in either IoT or big data. In both Vietnam and Malaysia emphasis was placed on AI, while big data and IoT were only marginally developed. $100 \%$ of the 57 Vietnamese curricula reviewed had AI content. Forty three (43) of the reviewed curricula of 35 IT departments in Malaysia have AI covered, via both embedding and newly developed.

\footnotetext{
${ }^{3}$ Universiti Putra Malaysia.

${ }^{4}$ MMU, Universiti Sultan Azlan Shah.

${ }^{5}$ Hanoi University; Industrial University in Hanoi; University of Information Technology, Vietnam National University in Hochiminh (VNU HCM); Vietnam-Germany University.

${ }^{6}$ Swinburne University of Technology, Sarawak Campus.

${ }^{7}$ Technology University, VNU in Hochiminh City.

${ }^{8}$ https://university2.taylors.edu.my/sites/default/files/pdf/Taylors-School-of-Computing-Prospectus \%2028_0.pdf.

${ }^{9}$ Hanoi University of Science and Technology.

${ }^{10}$ INTI International University; Limkowing university.
} 
The universities of both countries offered data-courses, such as: database analytics, database systems design, management, data warehouse, multimedia database, data structure and algorithms, etc., but without explicitly covering big data. In Vietnam only $11 \%(6 / 57)$ of the universities reviewed had big data content and only $9 \%$ (5/57 universities) had IoTs in the curriculum. In Malaysia, IoTs became more focused as a major at the Swinburne University of Technology, Sarawak Campus. The lack of IoTs was identified by Koo (2015), highlighting that few universities had courses dedicated to this emerging area of importance.

2) Developing new 4IR curricula of Malaysian Universities

Malaysian universities focused on developing new curricula more than embedding 4IR courses in the existing curricula. They had eight new AI curricula, two curricula of cloud-based technology. The Asia School of Business, a new MBA program in Kuala Lumpur developed with MIT Sloane School of Management, did not have specific curricula for 4IR technologies, but rather tried to provide students with short courses, including: AI, IoTs for business; Implementing Industry 4.0: Leading Change in Manufacturing and Operations; Understanding and Solving Complex Business Problems; Mastering Five Skills For Disruptive Innovation; and Achieving High Performance through Value Chain.

3) Differences of student learning outcome in 4IR competencies between embedding and new curricula

A key finding of note is that there was a difference in the intended student learning outcomes between curricula which embed content in already existing curricula versus those that have newly developed specifically 4IR-relevant curricula. The newly developed 4IR curricula focused on relevant competencies, whereas embedded additions did not. Table 3 provide examples that demonstrate this difference.

Although embedded curricula contained the 4IR areas of big data, AI and IoTs, the outcomes did not reflect competencies in these core technologies. The courses in the curricula were selected according to students' desire. For example, in the Universiti Teknologi MARA's curriculum, a robot design module was inserted into an existing program as representative of an AI-related minor, but did not aim to equip students with skills in developing AI application systems. As mentioned above, the traditional curricula focus almost on theory and single subject teaching and learning that cannot equip students with the necessary skills for the 4IR economy (Crawley, et al., 2007). In general, the current embedding curricula did not provide deep knowledge and practice of 4IR-relevant skills because they often provided only a minimal exposure with very general knowledge. This represents a significant gap in the HE coverage of 4IR-relevant graduate preparation, especially in Vietnam.

It is important to note that the content of 4IR-relevant technologies is only one element of the learning that is needed. Special pedagogical care is needed to develop the cognitive flexibility to apply the learning in different problem solving contexts. Key to this is authentic learning through problem-based and experiential pedagogies (National Academy of Engineering, 2017). The new 4IR 
Table 3. Differences of a stand-alone and an embedded IT 4IR curriculum.

\begin{tabular}{|c|c|c|}
\hline Curriculum & $\begin{array}{c}\text { New developing 4IR IT curriculum } \\
\text { Bachelor information technology and intelligent } \\
\text { systems engineering (Universiti Teknologi MARA (UiTM) }\end{array}$ & $\begin{array}{c}\text { Embedding 4IR IT curriculum } \\
\text { Bachelor of Computer Science (with IoT, Big data } \\
\text { and AI modules) (Hons) (Taylor's University) }{ }^{12}\end{array}$ \\
\hline Outcome & $\begin{array}{l}\text { The program has the objectives of producing graduates who are able to: } \\
\text { - demonstrate an understanding of Intelligence Information } \\
\text { - } \text { devstems concept. } \\
\text { tools used in industries. } \\
\text { - identify problems and apply artificial intelligence } \\
\text { methods to solve problems in relevant areas. } \\
\text { - present ideas effectively in written and oral form } \\
\text { in proposing the intelligent system applications. } \\
\text { - work in teams to develop intelligent systems applications } \\
\text { - that would be beneficial to the society and industry. } \\
\text { practice ethical values and professionalism in conducting } \\
\text { works related to Intelligent Information Systems development } \\
\text { - encompass data analytics in decision making for life-long learning. } \\
\text { - demonstrate entrepreneurial skills in marketing their applications. } \\
\text { exhibit good managerial and leadership skills. }\end{array}$ & $\begin{array}{l}\text { Provides students with the know-how and capability } \\
\text { to design, develop, integrate and maintain all types of } \\
\text { computer applications and systems, devise new and } \\
\text { better ways of using computer solutions and } \\
\text { technology to benefit society. } \\
\text { Students will explore software development and } \\
\text { all its related technologies, programming languages } \\
\text { and models, data structures and algorithms, } \\
\text { as well as innovation in the application of } \\
\text { computer solutions and technology; enhance their } \\
\text { entrepreneurial, problem solving, project } \\
\text { management and teamwork skills. }\end{array}$ \\
\hline Highlights & $\begin{array}{l}\text { To achieve these } 4 \text { IR-relevant competencies in AI, students were } \\
\text { not only provided with knowledge of AI fundamentals, but also } \\
\text { AI programming paradigm, language and intelligent decision making } \\
\text { support systems. The intended goals of the program also include } \\
\text { reference to actual situations-the industrial attachment work and } \\
\text { projects learning for students to practice developing intelligent } \\
\text { systems applications for real-world industries. }\end{array}$ & $\begin{array}{l}\text { The outcomes of embedded curricula did not } \\
\text { reflect competencies of core 4IR technologies. }\end{array}$ \\
\hline
\end{tabular}

curriculum highlights the importance of authentic learning experiences when it highlights that students will, "practice ethical values and professionalism in conducting works related to Intelligent Information Systems development with society and industry." The newly developed curricula are better places to implement innovative pedagogy and assessment practices. The newly developed 4IR-relevant curricula meet the requirements of educating engineers with competencies in different industrial fields but highly specialized in a specific industry as Crawley, et al. (2007) emphasized. Malaysia is in step with other leading 4IR ready countries in developing their HE 2018 strategy for new core 4IR curricula and courses, and in providing new AI, cloud computer technology and other new technology curricula.

\subsection{Integrating Creativity and Entrepreneurship, Lifelong Learning and Collaboration in Curricula}

Developing general competencies of creativity and entrepreneurship, lifelong learning, and collaboration is a focus in most of the curricula in Malaysia, but less so in Vietnam. Technopreneurship and entrepreneurship are general university courses in Malaysia. Most bachelor programs emphasized the develop${ }^{11}$ https://fskm.uitm.edu.my/v1/images/stories/academic/brochure/cs223.pdf.

${ }^{12}$ https://university.taylors.edu.my/en/study/undergraduate/computing/bachelor-computer-sciencehons.html. 
ment of these competencies in the curricula and embedded modules for student creativity development. Most of the IT curricula emphasized lifelong learning (Table 3). The trends found here reflect findings by Grapragasem, et al. (2014) confirming trends in Malaysian curriculum design that is focused on creativity, innovation, leadership and entrepreneurship development for students.

In Vietnam, the Government's guidance on developing lifelong learning habits and entrepreneurship has impacted universities' educating objectives. Almost $100 \%$ of the universities had entrepreneurial and start up orientations. However, only $22 \%$ of the 235 universities had specific entrepreneurial training and only $0.5 \%$ creativity training in the curricula. In 4IR-relevated curricula, creativity and entrepreneurship were rarely mentioned. These competency gaps in the Vietnamese engineering curricula are what Crawley, et al. (2014) indicate in other engineering curricula and what Tran, et al.'s (2014) criticize for the lack of creativity development in the Vietnamese universities' curricula.

The trend towards integrating core 4IR competencies with interdisciplinary and general competencies can be found almost exclusively in newly developed curricula. In Malaysia, courses on 4IR technologies were provided in combination with many other fields such as electrical and electronic engineering; electronics majoring in robotics \& automation; electrical and IT; Technology Innovation; and Technopreneurship. Creativity, teamwork and entrepreneurship were strongly emphasized in the new curricula as can be seen in Table 3 as an example. More combinations of IT with other science disciplines were found as well, especially biotechnology, IT and business and entrepreneurship. Among 74 Malaysian universities, 26 biotechnology curricula existed. This is the sort of transdisciplinary education that is needed to develop the cognitive capacities needed in the 4IR economy. In Vietnam, few efforts were noticed. A significant integration was found at the ELITE curriculum of Hanoi University of Science and Technology when they combined three fields together: cyber (IoT, AI, Big data); physical (nano, sensor, high tech materials) and bio. The Vietnam-German University $^{13}$ has an integrated program of electrical and IT for electrical engineers that enables students to design intelligent grid electrical systems. Vietnam Agriculture Academia ${ }^{14}$ provided a program titled "Business Management" that equipped students with 4IR-related technologies for agricultural application and business management. This included data processing in agriculture; E-commerce; machine learning; and AI contents. These integration curricula promised to offer students interdisciplinary knowledge as required, but they remain small in scale relative to the size of the population and the demand for improvement.

\subsection{Interdisciplinary, Project Learning and Industrial Practicum Based Curriculum}

Capstone projects and industrial practicums unite students together in collabor-

${ }^{13}$ http://www.vgu.edu.vn/vi/web/cms/study-program;jsessionid=31E666E5A12C27F0E79620D6435C 0AEF.

${ }^{14}$ http://www.vnua.edu.vn/. 
ative work and with industrial companies (Carter, et al., 2016; Crawley, et al., 2007). The universities of both countries put teamwork or collaboration development for students in their curriculum objectives and allocated time for students to practice in projects and industrial practicums. In Malaysia, practice in enterprises is a compulsory part of the university's IT engineer program and $100 \%$ of the IT bachelor programs provided time for students to work in industrial environments. University of Malaysia (UM) ${ }^{15}$ asked students to apply their skills and knowledge through the development of real world applications in their final year projects. At Taylor's University ${ }^{16}$, in additions to completing a Capstone Project (Part I, II), students must also have industrial training. The International Islamic University Malaysia ${ }^{17}$ required students to have a minimum of five and a half (5.5) months participating in an appropriate depth and breadth of experience; to integrate theories learned in the class with practical experience. The Malaysian Multimedia University $(\mathrm{MMU})^{18}$ specifically marketed itself as an entrepreneurial university with industry-ready programs. MMU established industry collaboration with ZTE, Microsoft, Intel and others to build labs in the campus for students to practice with industry. Bachelor of Science (Bioinformatics) at this MMU was intended to balance IT and the Life Sciences, while also providing training in specific applications; combined practical laboratory experience and problem-based learning, projects and industry experience alongside student presentations and lectures in small classes. This is an ideal setting for developing the competencies needed for the 4IR economy.

Most Vietnamese universities allocated time for students to gain practical skills in industrial companies. At Hanoi University of Science and Technology a joint program was developed by the University and Siemens Corporation (Lê, 2017). The University of Science and Technology, VNU in Hochiminh City in collaboration with Intel Corporation has developed laboratories for big data, IoT, learning machine, robotics, embedded systems, and Intelligent Transportation Systems ${ }^{19}$. In another example, students at the FPT University ${ }^{20}$ spent a year or more working in the IT and business companies. These are essential collaborations for the success of students in Vietnam and many more such curricula need to be cultivated. These efforts represent a step in the right direction, but need to be brought to scale.

The difference in the approaches to curriculum development between Vietnam and Malaysia could be due to the different education polices of the two countries. The Malaysian MoHE promulgated framework for HE 4.0, requires curriculum development to move away from single subject module design to${ }^{15}$ University of Malaya (UM).

${ }^{16}$ https://studymalaysia.com/what/course/taylor/0009160/.

${ }^{17}$ http://www2.iium.edu.my/kict/programmes-courses/undergraduate-programmes/bachelor-comput er-science.

${ }^{18} \mathrm{https} / / /$ www.mmu.edu.my/melaka/undergraduate-melaka/information-technology-computer-scien ce/bachelor-of-information-technology-hons-security-technology/.

${ }^{19} \mathrm{http}$ //www.hcmut.edu.vn/vi/welcome/view/cac-don-vi-truc-thuoc/-khoa--trung-tam-dao-tao/kho a-khoa-hoc-va-ky-thuat-may-tinh.

${ }^{20}$ http://international.fpt.edu.vn/home/campus-life/our-locations/hanoi/. 
ward interdisciplinary curriculum with an emphasis on 4IR competencies (MoHE, 2018). These strategies have impacted the universities by providing 4IR-relevant curricula. Malaysia and several other countries are already shifting policies, practices and curriculum in 4IR preparation, as Gleason (ed., 2018) has detailed. The Malaysian universities had developed new curricula, and integrated core 4IR curricula with other scientific and business fields and develop 4.0 competencies to prepare human capacities in the country. They focused on developing AI, cloud computing, entrepreneurial, lifelong learning and collaboration competencies, and directing more to IoT, big data in the coming years. Collaboration and industrial training is compulsory in engineering education in Malaysia and will be extended to either one or two year practicums in the industrial environment as announced in the new HE framework by the MoHE (2018). The Malaysian universities have overcome gaps of engineering curricula in business, entrepreneurial, effective communication and lifelong learning competencies that are indicated by Crawley, et al. (2014) as essential for success. They continue to lack critical CPS curricula. More work can be done, but Malaysia represents a nation on the right track, is ready for the 4IR as reported by the WEF and Kearney (2018).

Vietnam does not yet have the right curricula in place at the necessary scale to prepare its population for the 4IR knowledge and competencies needed. The country and the MOET implemented rather slow clear long term strategies for the 4IR. Vietnamese universities are at the initial phase of educating future ready graduates in 4IR-related skills. Most 4IR-relevant education was happening in increments and as separate pieces of learning. There was very little integration into a broader 4IR context and there was no specific focus on CPS. Only a few universities claimed specializations across disciplines with 4IR-relevant curricula, but the majority was siloed into single disciplines. Also, such programs at some universities were only accessible for high performing, talented students. Overall, efforts in delivering 4IR-related curriculum in Vietnamese universities are nascent and minimal. Only a few universities in Hochiminh and Hanoi Cities had the support from industry to have the necessary labs and equipment to test materials and train students in 4IR-related fields. Moreover, the number of students actually attending university in the first place in Vietnam remains very modest. Only $15 \%$ - $16 \%$ of the age 18 - 24 cohort had access to higher education (MOET, 2017) significantly less than the $70 \%$ of Malaysian students in the same demographic (MOE, 2015) and that means the workforce for the 4IR in Vietnam is not sufficient to transition Vietnam to the automation economy. The number and quality of PhD-level faculty at the Vietnamese universities were also lacking, with just $22.7 \%$ holding this degree and they did not have sufficient international publications and citations as a result. It is difficult for Vietnamese faculty to develop and teach interdisciplinary curriculum as they are most traditionally single discipline prepared at this moment (MOET, 2017). Malaysia is an example of relative $4 \mathrm{IR}$ readiness in human capital and is moving in the right direction, while Vietnam has not been able to develop and harness the appropriate 
high-quality curriculum to scale for its population.

\section{Conclusion and Suggestion}

\subsection{Conclusion}

This study identified two distinct approaches of HE providing 4IR-relevant curricula for engineers. They either embedded the curriculum in the existing curricula or developed new curricula. The study explores the unique characteristics of Malaysia's higher education curricular approaches in 4IR-relevant competencies and how they compare to those of Vietnam. The research demonstrates the ways in which Malaysia is better prepared for the 4IR relative to Vietnam and provides insights of potential adoption for ministries of higher education and industry. In Malaysia and in Vietnam there was some 4IR-relevant content being embedded into existing curricula, while there were also newly developed 4IR-relevant curricula emerging. Malaysian universities focused on developing new curricula, while most Vietnamese universities still used single subject module approaches and embedded some 4IR-relevent content into these existing courses. The study demonstrates that preparation for 4IR competencies offered by embedding courses can only provide general knowledge and initial exposure. Therefore newly developed interdisciplinary curricula with 4.0 industrial projects and industrial practicums are necessary for comprehensive preparation of 4IR competencies. The collaboration between industry experts and academicians allows industry to invest and trust in the knowledge their future employees are gaining. The data demonstrates that real CPS curriculum have not yet emerged in Vietnam or Malaysia.

This research illustrates some of the challenges Vietnam faces in the development of 4IR-relevant curriculum. Low enrollment rates, a lack of quality professors, and a lack of funding stall progress in these areas. Despite an understanding of the imperatives for survival in the automation economy, without foundational human resources and financial capital, it is difficult to create the necessary higher education curricula of sufficient quality in CPS and other 4IR-relevant fields.

\subsection{Suggestions}

1) To educate specialists in core $4 \mathrm{IR}$ competencies (e.g. AI, IoT, big data, CPSs) universities should apply the CDIO approach to develop new inter- and trans-disciplinary curriculum with a core 4IR technology major and integrate other disciplines. This should be combined with co-curricula pedagogies of practical experience in problem-based learning for better developing students' general competencies. The curriculum outcomes should be 4IR competencies for engineers that focus on both specialized and general competencies, especially related to 4IR, entrepreneurship, creativity, lifelong learning and collaboration.

2) Create special post-doctoral and $\mathrm{PhD}$ level funding mechanisms to either send students abroad or educate them in country, in order to develop high qual- 
ity teacher scholars who can teach and research in these fields.

3) The Malaysian and Vietnamese universities must focus more on preparing CPSs engineers to be ready for future development.

4) Universities should embed general/introduction 4IR courses in other non-engineering curricula to equip learners with general knowledge about the 4IR for better cooperation among engineers and experts from other fields in the 4IR context. Computer competency should be mandatory for all higher education students and faculty.

5) Nascent 4IR-ready countries should develop their long term plans for the 4IR implementation at both national and university levels. They should adopt CPS, IoT, AI and big data curricula from leading countries and invite experts in these fields to train students or use these curricula for reference when developing their own new curricula. Because emerging economies are faced with talent and funding shortages, they should place a greater emphasis on cooperation with other universities outside the home country to better develop an education ecosystem of knowledge and expertise around 4IR-relevant curricula and in training 4IR-ready graduates. Collaboration between government and industry is the crucial factor in supporting universities in this preparation and implementation of 4IR-ready graduates and the corresponding human capital needed for the automation economy. As the world becomes more connected, the lines of communication in higher education need to be kept open for upgrading and cooperating in preparing human resources. More funding from industries seeking diverse sets of employees should be allocated by industry representatives as well. The WEF 2018 report suggests that lagging countries prepare a minimum level of capability to leapfrog using opportunities provided by new technological paradigms (WEF \& Kearney, 2018).

6) As curriculum as an academic plan contains a number of elements (learning outcomes, models; organization and structure; teaching, learning and assessment strategies; module design) appropriate to the outcomes (O'Neill, 2015; Stark, 1986), research needs to be conducted to compare interdisciplinary 4IR curricula for countries with all their elements to learn from each other in developing appropriate 4IR-relevant curricula for themselves, but consistent for preparing real global Industry 4.0 engineers.

7) Curriculum design and implementation are both important, but according to Stark (1986), only curriculum implementation allows us to evaluate success and obstacles to improving. The study is limited in that surveys and direct observations of the curriculum implementation processes were not possible. Further research needs to be conducted on the curricular implementation of these efforts. Instruction and student work needs to be observed and evaluated to identify what is working well in practice and what the barriers to further success might be.

\section{Acknowledgements}

This research is funded by National Program for Education Science under grant 
number KHGD/16-20. DT007

\section{Conflicts of Interest}

The authors declare no conflicts of interest regarding the publication of this paper.

\section{References}

Bowen, G. A. (2009). Document Analysis as a Qualitative Research Method. Qualitative Research Journal, 9, 27-40. https://doi.org/10.3316/QRJ0902027

Carter, F. D., Ro, K. H., \& Alcott, B. (2016). Co-Curricular Connections: The Role of Undergraduate Research Experiences in Promoting Engineering Students' Communication, Teamwork, and Leadership Skills. Research in Higher Education, 57, 363-393. https://doi.org/10.1007/s11162-015-9386-7

Cicirello, V. A. (2008). An Interdisciplinary Course on Artificial Intelligence Designed for a Liberal Arts Curriculum. Consortium for Computing Sciences in Colleges: Eastern Conference, 23. https://pdfs.semanticscholar.org/fe45/2b318223a22d8d8303757effc133213903b8.pdf

Crawley, F. E., Malmqvist, J., Ostlund, S., \& Brodeur, R. D. (2014). Rethinking Engineering Education the CDIO Approach. Springer. https://doi.org/10.1007/978-3-319-05561-9

Ergezer, M., Kucharski, B., \& Carpenter, A. (2018). Curriculum Design for a Multidisciplinary Embedded Artificial Intelligence Course. Proceedings of the 49th ACM Technical Symposium on Computer Science Education, 1087-1087.

Gleason, W. N. (Ed.) (2018). Higher Education in the Era of the Fourth Industrial Revolution. Forthcoming Palgrave Press. https://doi.org/10.1007/978-981-13-0194-0

Grapragasem, S., Krishnan, A., \& NorhainiMansor, N. A. (2014). Current Trends in Malaysian Higher Education and the Effect on Education Policy and Practice: An Overview. International Journal of Higher Education, 3, 85-93.

https://doi.org/10.5430/ijhe.v3n1p85

Hecklau, F., Galeitzke, M., Flachs, S., \& Kohl, H. (2016). Holistic Approach for Human Resource Management in Industry 4.0. Procedia CIRP, 54, 1-6.

http://www.sciencedirect.com/ https://doi.org/10.1016/j.procir.2016.05.102

Infosys (2017). Amplifying Human Potential towards Purposeful Artificial Intelligence. India. https://www.infosys.com/

Iscoop (2017). Industry 4.0: The Fourth Industrial Revolution - Guide to Industrie 4.0. https://www.i-scoop.eu/industry-4-0/

Kalantari, A. et al. (2017). A Bibliometric Approach to Tracking Big Data Research Trends. Journal of Big Data, 4. https://doi.org/10.1186/s40537-017-0088-1

Koo, G. M. S. (2015). An Integrated Curriculum for Internet of Things: Experience and Evaluation. IEEE. https://doi.org/10.1109/FIE.2015.7344347 http://ieeexplore.ieee.org/iel7/7344010/7344011/07344347.pdf

Kurdahi, F., Abdullah, M., Faruque, A., Gajski, D., \& Eltawil, A. (2016). A Case Study to Develop a Graduate-Level Degree Program in Embedded \& Cyber-Physical Systems. SIGBED Review, 14, 16-21. https://doi.org/10.1145/3036686.3036688

Lê, C. (2017). Trường ĐHBK Hà Nội đẩy mạnh hợp tác với Côngty Siemens. https://www.hust.edu.vn/tin-tuc/-/asset_publisher/AKFI5qRls1e8/content/truong-hbk- 
ha-noi-tang-cuong-hop-tac-voi-cong-ty-sieme-1

Malaysian Digest (2017). How Do We Equip Malaysia’s Workforce for Industry 4.0. http://www.malaysiandigest.com/features/702866-how-do-we-equip-malaysia-s-workf orce-for-industry-4-0.html

Ministry of International Trade and Industry (2016). National Industry 4.0 Policy Framework.

http://grp.miti.gov.my/miti-grp/resources/Public\%20Consultation/Industry4.0Framew orkLayout_PublicReview(9Feb)V3_.pdf

MOE (Ministry of Education) (2015). Malaysia Education Blueprint 2015-2025 (Higher Education). Executive Summary. Kementerian Pendidikan Malaysia. https://www.um.edu.my/docs/default-source/about-um_document/media-centre/ummagazine/4-executive-summary-pppm-2015-2025.pdf?sfvrsn=4

MOET (2017). Evaluating 2016-2017 Academic Achievements of $\mathrm{He}$ and Targets for 2017-2018 Academic Year. In Higher Education Conference.

MOET (Ministry of Education and Training) (2017). Số liẹuthốngkê. https://moet.gov.vn/thong-ke/Pages/thong-ko-giao-duc-dai-hoc.aspx?ItemID=5137

MoHE (Ministry of Higher Education) (2018). Framing Malaysian Higher Education 4.0: Future-Proof Talents. https://drive.google.com/file/d/1081nH3_BgS_BSQYzFuvp8kWieRcr5s7t/view

Molluzzo, C. J., \& Lawler, P. J. (2015). A Proposed Concentration Curriculum Design for Big Data Analytics for Information Systems Students. Information Systems Education Journal, 13, 45-57. https://files.eric.ed.gov/fulltext/EJ1137322.pdf

Monnappa, A. (2017). Data Science vs. Big Data vs. Data Analytics. Simplilean. https://www.simplilearn.com/data-science-vs-big-data-vs-data-analytics-article

National Academies of Sciences, Engineering, and Medicine (2016). A 21st Century Cyber-Physical Systems Education. Washington DC: The National Academies Press. https://doi.org/10.17226/23686

National Academy of Engineering (2017). Engineering Societies and Undergraduate Engineering Education: Proceedings of a Workshop. Washington DC: The National Academies Press. https://doi.org/10.17226/23686

Nilsson, N. (1998). Artificial Intelligence: A New Synthesis. Burlington, MA: Morgan Kauffman Publishers, Inc.

O’Neill, G. (2015). Curriculum Design in Higher Education: Theory to Practice. Dublin: UCD Teaching \& Learning. http://researchrepository.ucd.ie/handle/10197/7137

Omar, W. (2017). Malaysian Higher Education: Redesigning Higher Education. In APAIE 2017 Conference \& Exhibition. https://apaiearc.nsysu.edu.tw/PPT/PPT_Malaysia.pdf

Passow, J. H., \& Passow, C. H. (2017). What Competencies Should Undergraduate Engineering Programs Emphasize? A Systematic Review. Engineering Education Journal, 106, 475-526. https://doi.org/10.1002/jee.20171

Rajkumar, R. (2012). A Cyber-Physical Future. Proceedings of the IEEE, 100, 1309-1321. https://doi.org/10.1109/JPROC.2012.2189915

Spector, L. (2006). Evolution of Artificial Intelligence. Artificial Intelligence, 170, 1251-1253. https://doi.org/10.1016/j.artint.2006.10.009

Stark, S. J. (1986). On Defining Coherence and Integrity in the Curriculum. Research in Higher Education, 24, 433-436. https://doi.org/10.1007/BF00991778

Thủ tướng Chính phủ (Prime Minister) (2017). Chỉ thịi số 16/CT-TTg "Về việc tăng 
cường năng lực tiếp cận cuộc cách mạng công nghiệp lần thứ 4". (Direction No. 16/CT-TTG on strengthening the accessing capacity to the 4th Industrial Revolution).

Törngren, M., Asplund, F., Bensalem, S., McDermid, J., Passerone, R., Pfeifer, H., Sangiovanni-Vincentelli, A., \& Schatz, B. (2017). Characterization, Analysis, and Recommendations for Exploiting the Opportunities of Cyber-Physical Systems. In H. Song, B. D. Rawat, S. Jeschke, \& C. Brecher (Eds.), Cyber-Physical Systems: Foundations, Principles and Applications. London: Academic Press.

Törngren, M., Grimheden, E. M., Gustafsson, J., \& Birk, W. (2015). Strategies and Considerations in Shaping Cyber-Physical Systems Education. In Workshop on Embedded and CyberPhysical Systems Education. New York: ACM. https://doi.org/10.1145/2829957.2829965

Tran, T. L., Le, T. T. T., \& Nguyen, T. N. (2014). Curriculum and Pedagogy. In Higher Education in Vietnam Flexibility, Mobility and Practicality in the Global Knowledge Economy. Basingstoke: Palgrave Macmillan.

WEF (2016). The Future of Jobs Employment, Skills and Workforce Strategy for the Fourth Industrial Revolution. http://reports.weforum.org/future-of-jobs-2016

WEF (World Economic Forum), \& Kearney, A. T. (2018). Readiness for the Future of Production Report 2018. World Economic Forum. http://wef.ch/fopreadiness18

Weltzien, C. I. (2016). Digital Agriculture-Or Why Agriculture 4.0 Still Offers Only Modest Returns. Land Technik, 71, 66-68.

Wyatt, R. (2000). Curriculum Descant: Interdisciplinaire $A I$ (p. 11). https://cs.brynmawr.edu/EIAIR/CurriculumDescant/9.html

Zanni, A. (2015). Cyber-Physical Systems and Smart Cities Learn How Smart Devices, Sensors, and Actuators Are Advancing Internet of Things Implementations. IBMdeveloper Works. 